\section{Two Lovely Black Eyes; Oh, what a surprise!}

\author{
Ian Pavord, ${ }^{1}$ Andrew Bush ${ }^{2}$
}

It has been said that adult chest physicians know three diseases-asthma, COPD and lung cancer-and cannot cure any of them. This is of course a libel both in terms of disease numbers and prognosis; however, the response to this libel seems to be to try to create new diseases that do not exist, rather than focus on new areas coming into adulthood, such as survivors of preterm and even late preterm birth. ${ }^{1-3}$ So ACOS, which might be thought to be some sort of demented lettuce, refers to asthma COPD overlap syndrome (or another, rather ruder acronym which we are tempted to use but with which we probably should not sully the pages of Thorax). This acronym has the demerits of combining what we argue to be two useless umbrella terms to make a third one that is even more useless.

In this issue of the Thorax, Peter Gibson and Vanessa McDonald ${ }^{4}$ review the published literature on ACOS published since our last review in $2009 .^{5}$ In total, $20 \%$ of patients could not find shelter under either the asthma or COPD umbrella, so a new one has to be sought. Their review makes depressing reading; quite unsurprisingly they found 'subgroups' within ACOS-the looming nightmare of ACOS type 1 , ACOS type 2 to ACOS type infinity beckons. ACOS may be characterised by a COPD-like systemic inflammatory profile; ACOS, asthma and COPD may be neutrophilic, eosinophilic or mixed; and bronchodilator reversibility fails to distinguish anything from anything else. The authors recommend jettisoning ACOS, with which view we concur; we would go further (hence, the unusual appearance of an editorial, aka rant, triggered by a review article). We have proposed that the umbrella terms, asthma and COPD, have long outlived their usefulness as well; ${ }^{6}$ personalised management

\footnotetext{
${ }^{1}$ Respiratory Medicine Unit, Nuffield Department of Medicine, University of Oxford, Oxford, UK; ${ }^{2}$ Paediatric Respiratory Medicine and Paediatrics, Royal Brompton Hospital and Imperial College, London, UK

Correspondence to Professor lan Pavord; Respiratory Medicine Unit, Nuffield Department of Medicine, University of Oxford, NDM Research Building, Old Road Campus, Oxford OX3 7FZ, UK; ian.pavord@ndm.ox.ac.uk
}

of airway disease is what we have advocated, and this has to be the way forward.

The writings of two great men, Richard Asher and Freddy Hargreave, are the bedrock on which thinking about airway disease rests. Richard Asher urged us to describe in plain English what we actually see ${ }^{7}$ and, in the context of airway disease, Freddy Hargreave did just that. ${ }^{8}$ So what, based on his scheme of things can go wrong with a biological tube? As we have argued elsewhere ${ }^{6}$ (and brazenly abuse our position as editors to elaborate here), there may be fixed narrowing, variable narrowing, inflammation and chronic infection. These process(es) may also have systemic effects. Surely each of these components should be addressed to develop a rational treatment programme, rather than the one size fits all, give lots of medicines to everyone approach which we fear is favoured by big pharma in particular. Therefore, we highlight an approach to each of these components in turn, which, if applied, should lead to individualised medicine for the individual patient.

Fixed airflow obstruction: The cause may be intrinsic narrowing of the airway, or loss of the supportive alveolar guy ropes. Definition of fixed obstruction should be easy-airflow obstruction after deployment of maximal medical therapies. There is the vexed question of what constitutes airflow obstruction. GOLD and others have elected to use a fixed value of $\mathrm{FEV}_{1}$ :FVC ratio at all ages rather than a developmentally appropriate definition, which makes no sense to some. ${ }^{9}$ However, arguing where to draw a line in the sand is not a topic worthy of too many column inches-who can interpret the significance of a height of $50 \mathrm{~cm}$ without knowing the age of the patient. What constitutes maximal medical therapies (usually a combination of prednisolone and acute short-acting bronchodilator) is more difficult. Clearly, the reason for wanting to know about it is to avoid escalating medicines when there is no further scope for improvement.

Variable airflow obstruction: There are multiple mechanisms; all that wheezes is not asthma is a well-hallowed cliché, but all that wheezes is certainly not bronchospasm.
Mechanism determines treatment-if intraluminal due to secretions, airway clearance and mucolytics if the root cause cannot be addressed; if intramural (airway smooth muscle contraction) then bronchodilators. Loss of alveolar guy ropes may also contribute to brisker bronchoconstriction in response to an adverse stimulus. Correlation between airway responsiveness and inflammation, and change in inflammatory profile and change in bronchial responsiveness, are weak to non-existent. ${ }^{10} 11$

Airway inflammation: There are numerous pathways and effector mechanisms of inflammation and its resolution, impairment of which can cause inflammation. However, inflammation may be beneficial, and it should not be modulated without due care and attention. In the context of airway disease, inhaled corticosteroids (ICS) are the treatment of choice for eosinophilic disease, and, if there is no response and the treatment (radically) is actually being taken, then steroid-resistant pathways must be sought. If neutrophilic, long-term low-dose macrolides has been shown to be beneficial at least in some groups; ${ }^{12-14}$ perhaps inhibiting neutrophilic airway inflammation more specifically is good if it is driven by tobacco smoke, but not if driven by bacterial infection. ${ }^{15} \mathrm{We}$ suggest that the mixed picture should be treated with both, and if there are no inflammatory cells present, then anti-inflammatory treatment is not escalated, unless there is evidence that a treatment responsive neurogenic or a chemically mediated pathway(s) is active. Crucially, we should not expect reducing airway inflammation to produce shortterm gains in symptoms or lung function. The main benefits appear to be a reduced risk of lung attacks. ${ }^{11} 1416$

Chronic airway infection: One of the great myths in medicine is that of the sterile airway; we now know that the normal airway teems with bacteria, fungi and viruses. Bacterial infection has come to the fore; from Copenhagen, the COPSAC study showed early neonatal nasopharyngeal colonisation with bacteria predicts poor respiratory outcomes, ${ }^{17}$ and bacterial isolation is reported to be as common as viruses in acute asthma. ${ }^{18}$ However, bacterial infection may not be causative, but a marker of an underlying immune abnormality, not least related to ICS therapy. We also do not want to risk the airway equivalent of antibioticassociated diarrhoea (whatever that may be, if anything) by using inappropriate antibacterial therapies, to say nothing of propagating resistant organisms in the 
community. But of course in some airway disease (cystic fibrosis, primary ciliary dyskinesia, bronchiectasis) the management of chronic airway infection is pivotal.

Systemic effects: It is clear that some patients with inflammatory airway diseases have evidence of systemic inflammation ${ }^{19}$ and might benefit from treatments that suppress this. What is less clear is whether the systemic inflammation drives the airway disease or vice versa (or both). The former is entirely possible as anyone who has encountered transplant-related graft versus host disease will recognise that the small airways are an immunologically vulnerable site. But can we detect this mechanism and is it modifiable?

Therefore, we are at a crossroads; we know that umbrella terms do not even keep off the rain; do we devise ever more 'overlap' syndromes, or go the Asher/ Hargreave route? The latter approach has driven the modest progress in new drug discovery we have seen in recent years, ${ }^{16} 20-22$ and our view is that deconstructing airways disease and challenging deeply held views is an absolute requirement for continued progress. There are numerous other obstructive airway diseases that we all see and are fond of categorising: cystic fibrosis, obliterative bronchiolitis, primary ciliary dyskinesia, (non-cystic fibrosis) bronchiectasis and the survivors of prematurity to name but a few. We could therefore construct 21 pairs of overlaps, or, if we allow more than one entity into the combination, more than 5000. Add in a few more obstructive diseases and the sky is the limit. Thoracic community, make a choice and act on it.
Competing interests None declared.

Provenance and peer review Commissioned; internally peer reviewed.

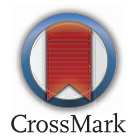

To cite Pavord I, Bush A. Thorax 2015;70:609-610.

Published Online First 13 May 2015

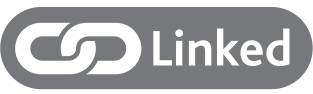

http://dx.doi.org/10.1136/thoraxjnl-2014-206740

Thorax 2015:70:609-610.

doi:10.1136/thoraxjnl-2015-207228

\section{REFERENCES}

1 Bolton CE, Bush A, Hurst JR, et al. Are early life factors considered when managing respiratory disease? A British Thoracic Society survey of current practice. Thorax 2012:67:1110.

2 Bolton CE, Bush A. Coming now to a chest clinic near you. Thorax 2013;68:707-8.

3 Bolton CE, Bush A, Hurst JR, et al. Lung consequences in adults born prematurely. Thorax 2015;70: 574-80.

4 Gibson PG, McDonald VM. Asthma -COPD overlap 2015: now we are six. Thorax 2015;70: 683-91.

5 Gibson PG, Simpson JL. The overlap syndrome of asthma and COPD: what are its features and how important is it? Thorax 2009;64:728-35.

6 Bush A, Kleinert S, Pavord ID. The asthmas in 2015 and beyond: a Lancet Commission. Lancet 2015:385:1273-5.

7 Asher R. Talking sense. London: Pitman Medical, 1973.

8 Nair P, Hargreave FE. The definition and diagnosis of asthma. Clin Exp Allergy 2009;39:1652-8.

9 Quanjer PH, Enright PL, Miller MR, et al. The need to change the method for defining mild airway obstruction. Eur Respir J 2011;37: $720-2$.

10 Green RH, Brightling CE, Woltmann G, et al. Analysis of induced sputum in adults with asthma: identification of subgroup with isolated sputum neutrophilia and poor response to inhaled corticosteroids. Thorax 2002;57:875-9.

11 Green RH, Brightling CE, McKenna S, et al. Asthma exacerbations and sputum eosinophil counts: a randomised controlled trial. Lancet 2002:360:1715-21.

12 Wong C, Jayaram L, Karalus N, et al. Azithromycin for prevention of exacerbations in non-cystic fibrosis bronchiectasis (EMBRACE): a randomised, double-blind, placebo-controlled trial. Lancet 380:660-7.

13 Brusselle GG, VanderStichele C, Jordens $P$, et al. Azithromycin for prevention of exacerbations in severe asthma (AZISAST): a multicentre randomised double-blind placebo-controlled trial. Thorax 2013;68:322-9.

14 Albert RK, Connett J, Bailey WC, et al. Azithromycin for prevention of exacerbations of COPD. $N$ Engl J Med 2011;365:689-98.

15 Rennard SI, Dale DC, Donohue JF, et al. CXCR2 antagonist MK-7123-a phase 2 proof-of-concept tria for chronic obstructive pulmonary disease. Am J Respir Crit Care Med 2015;191:1001-11.

16 Haldar P, Brightling CE, Hargadon B, et al. Mepolizumab and exacerbations of refractory eosinophilic asthma. N Engl J Med 2009;360:973-84.

17 Bisgaard H, Hermansen MN, Buchvald F, et al. Childhood asthma after bacterial colonization of the airway in neonates. N Engl J Med 2007;357:1487-95.

18 Jackson DJ, Johnston SL. The role of viruses in acute exacerbations of asthma. J Allergy Clin Immunol 2010;125:1178-89.

19 Gan WQ, Man SFP, Senthilselvan A, et al. Association between chronic obstructive pulmonary disease and systemic inflammation: a systematic review and a meta-analysis. Thorax 2004;59:574-80.

20 Nair P, Pizzichini MM, Kjarsgaard M, et al. Mepolizumab for prednisone-dependent asthma with sputum eosinophilia. N Eng/ J Med 2009;360: 985-93.

21 Corren J, Lemanske RF, Hanania NA, et al. Lebrikizumab treatment in adults with asthma. N Engl J Med 2011;365:1088-98.

22 Wenzel S, Ford L, Pearlman D, et al. Dupilumab in persistent asthma with elevated eosinophil levels. N Engl J Med 2013;368:2455-66. 